\title{
Curriculum policy reform in an era of technical accountability: 'fixing' curriculum, teachers and students in English schools
}

\section{Christine Winter}

To cite this article: Christine Winter (2017) Curriculum policy reform in an era of technical accountability: 'fixing' curriculum, teachers and students in English schools, Journal of Curriculum Studies, 49:1, 55-74, DOI: 10.1080/00220272.2016.1205138

To link to this article: http://dx.doi.org/10.1080/00220272.2016.1205138
(c) 2017 The Author(s). Published by Informa UK Limited, trading as Taylor \& Francis Group
册 Published online: 05 Jan 2017.

Submit your article to this journal

山ll Article views: 682

Q View related articles 5

View Crossmark data $₫$ 


\title{
Curriculum policy reform in an era of technical accountability: 'fixing' curriculum, teachers and students in English schools
}

\author{
Christine Winter \\ School of Education, University of Sheffield, Sheffield, UK
}

\begin{abstract}
Drawing on a Levinasian ethical perspective, the argument driving this paper is that the technical accountability movement currently dominating the educational system in England is less than adequate because it overlooks educators' responsibility for ethical relations in responding to difference in respect of the other. Curriculum policy makes a significant contribution to the technical accountability culture through complicity in performativity, high-stakes testing and datafication, at the same time as constituting student and teacher subjectivities. I present two different conceptualizations of subjectivity and education, before engaging these in the analysis of data arising from an empirical study which investigated teachers' and stakeholders' experiences of curriculum policy reform in 'disadvantaged' English schools. The study's findings demonstrate how a prescribed programme of technical curriculum regulation attempts to 'fix' or mend educational problems by 'fixing' or prescribing educational solutions. This not only denies ethical professional relations between students, teachers and parents, but also deflects responsibility for educational success from government to teachers and hastens the move from public to private educational provision. Complying with prescribed curriculum policy requirements shifts attention from broad philosophical and ethical questions about educational purpose as well as conferring a violence by assuming control over student and teacher subjectivities.
\end{abstract}

\section{KEYWORDS}

Curriculum; policy; accountability; Levinas; ethics

\section{Introduction}

Accountability is an important concept in the distribution and deployment of public resources, but questions exist over what kinds of accountability are appropriate and how evaluation of accountability should be conducted. Educational accountability of a technical kind is promoted globally in different ways to different extents through regimes of performativity, high-stakes testing and Datafication. Ranson argues that since the late 1970s in England, the education sector has been dominated by 'a regime of neo-liberal corporate accountability' (2003, p. 459). The aim, in the view of Stobart (2008), is to raise educational standards to meet the demands of the knowledge-based economy for enhanced human

CONTACT Christine Winter c.winter@sheffield.ac.uk

(c) 2017 The Author(s). Published by Informa UK Limited, trading as Taylor \& Francis Group.

This is an Open Access article distributed under the terms of the Creative Commons Attribution-NonCommercial-NoDerivatives License (http://creativecommons.org/licenses/by-nc-nd/4.0/), which permits non-commercial re-use, distribution, and reproduction in any medium, provided the original work is properly cited, and is not altered, transformed, or built upon in any way. 
capital in an increasingly competitive international economic environment. Educational problems in England, such as declining standards, the attainment gap between advantaged and disadvantaged students and the nation's declining rank in international league tables, are signalled as resulting from poor levels of public education accountability (DfE, 2010a). Taking these discourses of policy problems/drivers at face value leads to the question of how to solve them. In other words, in an educational culture in which performance, expressed as measured productivity or output dominates as the key indicator of technical accountability, what policy levers and mechanisms exist by which the assumed policy problems may be resolved and educational performance thereby enhanced?

In the case of curriculum, policy levers summoned to solve educational accountability problems consist of the following: tightening curriculum control by means of a technical, 'one-size -fits all', standardized curriculum configuration (with prescribed outcomes), specification of curriculum knowledge, together with high-stakes standardized testing and statistical analysis and reporting. 'Datafication' (Lingard, 2011) or codification of assessment results in statistical form and allocation of borders assigning value to numerical scores serve as the means of evaluating whether or not the prescribed curriculum outcomes have been achieved, thereby signifying improved or declined student performance and hence configuring the basis of accountability judgements. The main argument of this paper is that the current dominance of technical accountability in curriculum is less than adequate because it overlooks educators' responsibility for ethical relations in responding to difference. Drawing on Levinasian thought, the paper explores teachers'/education stakeholders' experiences of curriculum in 'disadvantaged' English secondary schools in order to understand ethical relations arising when technical accountability dominates curriculum and assessment policy reform.

To contextualize the discussion, I begin by outlining three characteristics of the current technical accountability culture in education: performativity, high-stakes testing and datafication, before indicating the wealth of international critical policy research conducted in the field in the last 15 years. I turn next to explain the powerful influence of curriculum in constituting student (and teacher) subjectivities. Two conceptualizations of subjectivity that respond differently to warrants of technical accountability and ethical responsibility are examined in the paper's second part. In part 3, I present the methodology and analysis of data collected during an empirical enquiry into teachers/stakeholders' experiences of curriculum policy reform in English secondary schools. The fourth and concluding part of the paper returns the discussion to wider ethical implications of curriculum policy dominated by technical accountability.

\section{Part 1: performativity, high-stakes testing and datafication}

The rise of techniques and technology after World War 2, together with the flourishing of liberalism, with its economic focus and endorsement of the individual from the 1960s onwards, gave rise to a connection between technology and profit that marks the emergence of the concept of 'performative improvement' (Lyotard, 1984, p. 45). Performative improvement is achieved when technology follows the principle of minimization of input and maximization of output, in other words the 'best possible input-output equation' for optimal efficiency. Under the banner of efficiency, educational goals shift from universal narratives of truth, justice or beauty, to technical efficiency (ibid., p. 44). The objective is to optimize the education system's performance and therefore - it is presumed-under the operation 
of technical rationality, to maximize its accountability. Manifest in education systems via the drive to enhance productivity in order to meet the pragmatic needs of the economy by increasing the supply of functionally skilled workers, Ball describes performativity as:

... a technology, a culture and a mode of regulation that employs judgements, comparisons and displays as a means of incentive, control, attrition and change-based on rewards and sanctions ... The performances (of individual subjects or organisations) serve as measures of productivity or output, or displays of 'quality' or'moments' of promotion or inspection. As such, they stand for, encapsulate or represent the worth, quality or value of an individual or an organisation within a field of judgement. (2003, p. 216)

Whilst the concept of performativity carries an aura of objectivity, certainty and transparency, its activities reduce complex social processes involved in the educational experience and the formation of subjectivities to codes, statistics and categories (Ball, 2003). Performativity provides a totalized audit mechanism within education systems by issuing examination scores, rankings, attainment indicators, levels of progress, assessment benchmarks and targets. An important procedure by which performativity is enacted is through the high-stakes testing of students, the primary aim of which is to raise standards of test and examination performance compared with national and other benchmarks and with other schools, through consistent, regular and frequent stock-taking (Barber, 2007). Comparison of students' examination scores forms a significant component of the performative education system, as individual students', school subjects', schools', Local Authorities' and nations' scores are ranked and borders are inserted between ranks to name and distinguish those individuals and institutions deemed to 'succeed'from those deemed to'fail'. As part of the technical-rational accounting system, high-stakes testing is most efficiently managed using data.

Datafication forms a totalizing technical discourse governing the constitution, justification, implementation and evaluation of curriculum policy. Lingard (2011) explains how our complex post-Cold War world of 'ontological insecurity', formed through fundamentalist terrorism, neo-liberalism and new technologies, is seemingly rendered manageable via'policy as numbers' techniques. These offer individuals, schools and nations what are assumed to be valid, reliable and therefore objective measures of accountability. Facilitated by technical advances in computing capacity and levels of analytical sophistication, datafication, on the one hand, allows people who want to be counted to be counted so that social inequalities can, seemingly, be identified and addressed through policy. On the other hand, datafication involves categorizing student and teacher subjectivities, in other words, codifying who and what people are (and even, what they will become), making them amenable to regulation and control, whilst at the same time hiding the technologies that conceptualize and constitute the data which, it is claimed, represent them (Rose, 1999). Datafication provides one form of educational accountability, but carries certain statistical requirements for codification and comparison, and, in turn, these require standardization of inputs, processes and outputs of the curriculum system. Examples include specified curriculum objectives and knowledge configuration, assessment criteria and benchmarks. Standardization facilitates codification for statistical representation and analysis, but can only be achieved by naming, defining and reducing meaning, in other words, 'fixing' meaning to fit system input, process and output requirements.

Educational accountability of the technical kind outlined above has been researched globally during the last 15 years, to form a rich collection of international critical policy scholarship. In the USA, researchers investigating the impact of 'test-based metrics' (Henig, 
2013), mainly through theoretical ( $\mathrm{Au}, 2008,2011)$, metasynthesis ( $\mathrm{Au}, 2007)$, national (Pedulla et al., 2003) or state-based enquiries, include Abrams (2004), Baker et al. (2010), Barrett (2009), Darling-Hammond (2010), Hursch (2013), Lipman (2013); and Perreault (2000). Examples of Australian contributions to the field range from global (Lingard, Martino, \& Rezai-Rashti, 2013; Sellar and Lingard 2013) to national (Dulfer, Polesel, \& Rice, 2012; Polesel, Rice, \& Dulfer, 2014; Lingard, Sellar, \& Savage, 2014; Lingard, 2011; Lingard \& Sellar, 2013; Lingard, Creagh, \&Vass, 2012) and state (Thompson, 2012) and finally school enquiries such as Comber (2012), Comber and Nixon (2009), Singh, Thomas, and Harris, (2013), Gerrard and Farrell (2013) and Keddie (2013). Recent English studies, such as Perryman (2006), Braun, Ball, Maguire, and Hoskins (2011), Ball, Maguire, Braun, and Hoskins (2011a, 2011b) and Maguire, Hoskins, Ball, and Braun (2011) focus on school policy enactment, with Ball (2003) and Leat, Livingston, and Priestley (2014) researching the national picture. Scholars who have ventured beyond structuralist and Foucauldian analytical perspectives, such as Sellar $(2009,2013)$ and Macedo (2013), consider the implications of technical accountability for social justice. But naming, defining (i.e. 'fixing') the words 'equality', 'equity', 'social justice' in school settings of complex, fluid human subjectivities runs up against issues of applying a totalizing economy on what are assumed to be calculable human subjects (Rose, 1999). By drawing on Levinasian ethics as a critical lens to interrogate student and teacher subjectivities under conditions of curriculum policy reform, this paper offers something innovative to the field of critical policy and curriculum studies.

\section{The power of curriculum}

The approach to standardization and associated tightening of control over curriculum practices through curriculum policy described above fits Lingard et al.'s (2013) proposal that increasingly, curriculum is understood by educational researchers 'as systemic policy ... implemented or enacted in schools and classrooms through pedagogy and framed by systemic evaluation, assessment and testing policies' (p. 549). Presupposing an interpretation of curriculum in a technical sense as specified knowledge content and objectives conveys an impression of objectivity and value-neutrality, whilst hiding curriculum's inevitable value-laden character. Likewise, in accordance with its Latin derivative 'currere' meaning 'a course to be run' (Cherryholmes, 2002, p. 116), curriculum establishes the seemingly unproblematic content and boundaries for what is included and excluded in the planned educational experience as well as expectations of future educational outcomes. Yet, enhancing the interpretation of curriculum above with Rizvi and Lingard's definition of policy as 'the authoritative allocation of values' (2010, p. 7) an alternative perspective arises. This alternative perspective recognizes curriculum policy as 'a cornerstone of educational governance' (Gerrard \& Farrell, 2013, p. 4) because in addition to designating and legitimating official school knowledge, objectives, skills and assessment criteria, curriculum policy also influences pedagogical practices and relationships, the organization of school space and time (ibid.) and teacher and student meaning-making (Todd, 2001). As such, it forms a powerful totalizing mechanism over students' and teachers' experiences of education. Todd (2001) describes how curriculum is the 'raw material' of education and students may accept, reject or rewrite curriculum. In this sense, curriculum serves an important role in influencing student subjectivity. Education is one process by which the person becomes a subject or self. Curriculum, pedagogy and relationships constitute student subjectivity by influencing or shaping who 
and what students are and become. In the next part of the paper, I discuss two understandings of subjectivity and educational accountability/responsibility to inform the empirical enquiry to follow.

\section{Part 2: two conceptualizations of subjectivity}

\section{Subjectivity and technical accountability}

The modern Kantian conception of subjectivity and education is understood through the lens of humanism as the development of the rational, autonomous subject. The subject achieves autonomy, rationality and criticality through education (Biesta, 2010, p. 76), where the role of education is to release the learner from the binds of indoctrination and inculcation to bring out her/his potential as an autonomous subject with the free will to act rationally. The particular kind of human subject generated through this mode of thinking fits a humanist mould: 'the idea that it is possible to know and express the essence or nature of the human being, and also that it is possible to use this knowledge as the foundation for subsequent action' (Biesta, 2010, p. 78). Under Kantian humanism, being and becoming in the educational project is founded on a particular truth about what humans are and how they should act. The notion of humanness is specified in advance and education, under the spell of this specification becomes totalizing and reproductive. It governs educational discourses and blocks the emergence of alternative notions of being and becoming. Teaching is understood as sets of techniques or procedures used to deliver knowledge, values and reasoning skills into students' minds and souls to make autonomy possible (Biesta, 2010, p. 65) or, alternatively and according to the Socratic view of maieutics, teaching is about bringing the student into the world, as in the 'birth' of the knowledge and values that lie innate within the individual through the actions of the teacher-midwife (Strhan, 2012, p. 22).

Under the Enlightenment presumption that education guides the subject into an autonomous existence governed by reason lies the idea that the human subject, through education, becomes like me, another human subject. Thus, we are united in our humanness as members of the community of humans. Biesta explains one of the problems of this kind of thinking:

... it posits a norm of humanness, a norm of what it means to be human, and in so doing excludes those who do not live up to or are unable to live up to this norm ... this form of humanism ... specifies a norm of what it means to be human before the actual manifestation of 'instances' of humanity. It specifies what the child, student or newcomer must become before giving them an opportunity to show who they are and what they will be. (Biesta, 2010, p. 79)

Difference is thereby suppressed and education adopts a reproductive role in normalizing what it means to be human.

An example of how the subject is inducted into the world of presence and sameness as an autonomous, rational individual is by means of the modern school curriculum. The standardized programme, or technical curriculum (Au, 2008, p. 505), consists of pre-defined objectives, prescribed knowledge configurations, such as core knowledge, competencies or concepts (Winter, 2011) and standardized assessment regimes. Such a curriculum centres round totalized discourses whereby knowledge becomes trapped or fixed in conceptual categories and language (Winter, 2009). These concepts can be, it is assumed, unproblematically defined and applied, outcomes of the educational endeavour judged and measured according to pre-specified criteria, leaving little space for alternative ways of thinking. 
Curricula, under this approach, become controlling, driven by rationality and assumed clarity of meaning, rather than ethical (Eppert, 2008, p. 71). There is little scope within such curriculum discourses for questioning knowledge, concepts or the unstable meanings of words, in order to welcome the other. Prescription, standardization and assumed rigour preclude other ways of thinking, other ways of being. Conformity and calculability elide the singularity and uniqueness of the other (Todd, 2003a, p. 61).

Ball, Maguire, Braun, Perryman, and Hoskins (2012) describe regulatory regimes that are activated under the technical curriculum approach in the age of performativity as 'deliverology'. In the case of the English school system, the main focus of teaching, learning and relationships becomes the raising of predetermined standards as measured by the percentage of top examination grades. Key features of 'deliverology' include 'comprehensive' and 'accurate' assessment data on student achievement, target- and trajectory-setting, consistent, regular and frequent stock-taking and reporting and regular tracking of student progress (ibid., p. 514). Given the significance of raising standards of student achievement to the school's success and, in some cases, its survival, examination results become the main focus of attention for school staff. The language used to describe the emphasis on, even obsession with, grades by teachers in schools as 'bringing a lens to bear', 'a close-up view', 'bringing things into visibility' (ibid., p. 517) corresponds with the notion of the 'fix'. But this is not an innocent or neutral gaze, since the prime purpose of bringing everything into view is to know and categorize students according to the rules and mechanisms of the system. Policy naturalizes testing and reporting activities, valuing them as obvious and unquestionable and enlisting them in the service of achieving required ends, again, as dictated by the system. Echoing through the voices of teachers to be heard later in the paper, curriculum policy reform and its adjunct performativity produce new kinds of student and teacher subjectivities, relationships, new forms of human existence (Ball, 2003).

\section{Subjectivity and ethical responsibility}

Levinas's (1969) work challenges the modernist view of subjectivity and education, replacing it with a view of how humans become subjects through 'responsible subjectivity' arising from ethical human relationships. Arguing that ethics comes before everything-ethics is 'first philosophy' and 'a relation of responsibility to the other' (Strhan, 2012, p. 21) -the ethical relation to the other emerges from a pre-originary structure of being, beyond and before the invention of ontology. Levinasian ethics defies universalization and standardization because it is not bound by the kinds of totalizing discourses conferred by Enlightenment thinking, but goes beyond such philosophical programmes as'an exterior relation to being, an otherwise than being' (Todd, 2003b, p. 2). Levinas wrote: '... pre-existing the plane of ontology is the ethical plane' (1969, p. 201). It is in the ethical relationship and through language that the subject comes into being. Subjectivity is constructed through the relation between the subject and the other. As a singular subject, I am summoned by a moral imperative presented by the other and I respond, taking responsibility for the other in such a way that is exterior or prior to any totalizing frameworks. Responsibility here is neither a rational relationship of exchange nor an understanding that the other should be brought into the totality of the same, that is, inducted into modernist frameworks of thought to make her like me, because this will deny her alterity, her difference. Instead, by listening to and being 
receptive to the otherness of the other, the other opens me by her demand to respond. I learn from and respond to her singularity, uniqueness and needs.

This way of thinking accepts that the subject has no pre-ordained nature or essence and that there exist no predetermined rules or frameworks (such as humanism) into which the subject should be inducted. Instead, understanding the distance, strangeness and separation between myself and the other and respecting the idea that selfhood comes from outside totalized philosophical programmes, from the exterior, 'brings me more than I contain' (Strhan, 2012, p. 23). The 'I' challenges the security and unity of the self as an interior being shaped by dominant discourses of domestication, destabilizing these structures and opening to an exteriority that has not been thought before. Levinas offers hope for a new and refreshed consideration of curriculum outside the boundaries of technical accountability. By challenging the assumed accurate and fixed meanings of words and numbers constituting discourses of performativity, high-stakes testing and datafication, by defying the constraining template of humanism, Levinas opens a space for thinking otherwise, unconstrained by externally prescribed specifications. His commitment to the ethical relation to the other drives our thinking beyond the dictates of the technical, beyond naming students using 'objective' criteria and reductive grades, ranking them in an hierarchy of 'success' and 'failure', fixing them to match some person's or group's ideas of what it means to be 'educated' and 'human', regardless of difference.

A change of tone of expression is required as I explain how the enquiry was conducted.

\section{Part 3: the empirical enquiry}

\section{Methodology}

The enquiry began as a meeting of geography and history teachers and education stakeholders to discuss responses to recent curriculum policy reforms. I invited colleagues to share views about General Certificate of Secondary Education (GCSE) attainment in local 'disadvantaged' secondary schools. I was interested to discover their perspectives on the current and future influence of recent policy reforms on GCSE geography and history examination performance. In England, student performance in GCSE examinations (usually taken by 16 -year-olds) constitutes a significant indicator for accountability in national league tables. If less than $35 \%$ of pupils at the end of Key Stage 4 (KS4) achieve five or more GCSEs $A^{*}-C$ (or equivalents) including English and mathematics, then the school is considered to be 'under-performing' (DfE, 2010a). ${ }^{1}$ Between 2012 and 2013, in one local authority in the north of England, although the percentage of top grades $\left(>5 A^{*}-C\right.$ ) rose in both low-and-high attaining non-selective state schools, the attainment gap between the two categories of schools remained at $25 \%$ over the same period. The meeting under discussion here was organized to plan, design and conduct collaborative research with practitioners and policy-makers, arising from issues identified and bearing potential for improving policy and practice. At the first meeting, five participants discussed the topic of 'GCSE attainment and education policy' in two groups (one group of three, the other of two; I joined the group of two), through 'inter-professional focussed conversations.' ${ }^{2}$ The mix of professions in the groups ensured that practitioners and policy-makers talked directly with each other, making these groups different from individual interviews and focus groups with members with shared characteristics. I provided specific questions ${ }^{3}$ in case the groups ran out of topics and 
the conversations were recorded. I later conducted face-to-face, semi-structured interviews with two Geography teachers who taught at the same 'disadvantaged' school as each other and had not participated in the first meeting. University ethical approval and participants' informed consent were obtained before any data collection began. Given the sensitivity of the topics under discussion, protection of participants' identities and institutions remains top priority.

Recordings were transcribed and a first-stage manual analysis took place using Braun \& Clarke, 2006 approach, producing 28 initial codes which were collapsed into 15 themes. Following transcription of the individual interviews with two Geography teachers, second-stage analysis built on the first-stage codes and themes to produce 14 codes and three themes: performativity (7 codes), curriculum configuration (4) and academic culture (3). Reading and re-reading all the data revealed a recurring pattern of a normalization process of curriculum control through regulation and standardization. Closure, limits, rules, programmes, monitoring and surveillance technologies arose persistently in participants' accounts. Such systems of regulation and control illustrate the kind of totalizing discourses that Levinas calls us to overcome in order to open a space for thinking in which we retrieve our ethical responsibility to the other. During the second analysis stage, I followed Kierkegaarde's (1850, p. 357f) advice to 'go for a walk' in the data and the idea of the 'fix' emerged in the form of government intentions to 'mend' (repair, improve) the so-called unaccountable education system by 'dictating' (pinning down, defining, standardizing) certain ways of thinking, acting and being for students and teachers. In the final stage of analysis, I identified the concept of the 'fix' embedded within 14 (of the 15) themes and reorganized these in relation to three categories: curriculum, students and teachers. Member checks of transcript extracts to be included in this paper were carried out.

Although the number of participants was small, the meeting brought together colleagues with similar (they were all interested in the health of school geography and history), yet different (teachers and other stakeholders/policy-makers) professional interests in a relaxed and trusting atmosphere. I felt it important for teaching and non-teaching colleagues to listen to each others' perspectives (Coffield, 2012). The discussions were open and generative, providing an unexpected opportunity to gather data untethered from conventional semi-structured questions posed in individual or focus group interviews. Conversations were surprisingly frank and explanatory, as participants were compelled to explain their points to those of a different subject and professional stance. The meeting took place in a neutral space, away from participants' workplaces, and this, together with my expressed commitment to confidentiality seemed to dispel the perception of risk of accusations of disloyalty. Semi-structured individual teacher interviews took place later in the teachers' school. These were recorded, transcribed and analysed.

\section{The analytical concept of the 'fix'}

'Fix' is a slippery word. Every time I try to pin it down, it slides off in a different direction. I fix a light by replacing the bulb. I fix the dye of my jacket. The fixed price of an item in a shop means I cannot negotiate a discount. I fix my gaze on the bridge and then fix its location on the map. I sometimes get in a fix by failing to do something I promised to do. The British Prime Minister claimed that government policy would fix the country's education system (DfE, 2010a, Foreword), but I claim that government solutions are a stage-managed 'fix-up'. 
The instability of word meanings illustrates how language defies accurate definition and totalization. I turn now to the interplay and non-presence of these meanings of the concept of 'the fix' which emerged from the analysis of the data. Data illustrate many ways in which curriculum policy operates as a driver of a technicalrational system of accountability through the imposition of frameworks of totalization. By compelling teachers and students to comply with its dictates, curriculum policy 'fixes' the knowledge configuration of the school curriculum, its structure and processes, at the same time as 'fixing' teachers and students as subjects.

\section{Fixing curriculum, teachers and students}

\section{'Fixing' curriculum}

\section{Focus on specific subjects, core and content knowledge}

Given the most important indicator of GCSE examination performance in English school league tables is the percentage of grades $A^{*}-C$ (including English and mathematics), these two subjects assume considerable significance in the high-stakes assessment regime. In attempts to increase students' grades, attention in participants' schools 'fixed' on the two specific curriculum subjects of literacy and numeracy, and, in the process, deflected from other subjects (Sahlberg, 2011, p. 100). For example, two primary teachers in one school were employed to withdraw students from the regular timetable to teach them literacy through phonics. Participants agreed that history and geography lost teaching time and status to literacy and numeracy, arguing that this had a detrimental effect because missed lessons meant declining performance in geography and history tests and students then decided not to study these subjects at GCSE. At the same time, a question is raised of the implications of basic technical skills in reading, writing and mathematics replacing an in-depth understanding of values and sensibilities of place, space and time conferred through geography and history.

The English Baccalaurate (E-Bac) ${ }^{4}$ and core knowledge represent other 'fixes' on specific curriculum subjects. School E-Bac scores are published in examination league tables. At the time of its introduction, in order to qualify for an E-Bac, a student had to gain five or more top GCSE grades $\left(\mathrm{A}^{*}-\mathrm{C}\right)$ at in English language, mathematics, science, a foreign language and either history or geography. The E-Bac thus'fixed' or privileged six traditional academic curriculum subjects and at the same time excluded more practical subjects such as art, design and technology, drama, food science, music, religious education and sports studies. The focus on a narrow range of academic subjects and knowledge 'missed the mark' in one participant's school:

I fear it's a very one person or a small narrow group drive to make education fit their ideologies and their perception on what education should look like. For me it doesn't fit the skills base that's required out there ... the education system and the specifications that we're working towards ... seem to develop those that want a test in just academic ability, memory, just reading and writing. (Jo, teacher)

In 2010, the government announced that school curriculum knowledge was lacking in intellectual challenge, and it would introduce'a tighter, more rigorous, model of the knowledge which every child should expect to master [sic] in core subjects at every key stage' (DfE, 2010a, para 11). 'Fixing' curriculum knowledge involves the identification and prescription of a bounded 'core' of disciplinary knowledge deemed to form the 'best' body of knowledge 
for the curriculum. It is defined and promoted as the knowledge that 'All children should acquire' (ibid., para 4.1) or' ... be expected to master' [sic] (para 4.6); that all teachers should 'know how to convey effectively' (ibid., para 4.8) and against which students will be tested (para 4.2). This was experienced by teachers as an increase in the level of difficulty of the examination questions. Participants described this as 'a big shift in the culture of that GCSE'; 'more of an ' $A$ ' level slant to the ways the questions were worded'; 'they're drilling down in more narrow theoretical areas of Geography rather than the wider human-physical interactions' (Jo) and using 'more inference rather than explicit instruction you know, 'use a case study' would have been on a past paper, this one was 'here's the theory', but without telling the kids directly that they ought to apply the theory to the case study (Gordon, teacher). One participant remarked how the government had narrowed the curriculum to a core content:

... what's been happening is the notion of the core ... the way in which it's beginning to appear in Geography is that there's a notion of a body of content. For example at A-Level there's been fears going on for 20 years that it's possible to study an A-Level and veer away from the physical towards human and environmental geography. So, in order to address and correct that, what we're seeing is a core curriculum in effect or at least a core framework, saying there must be a balance of human and physical at GCSE and A-Level. (Graham, stakeholder)

Whilst the British government argues that a common core, disciplinary-based curriculum is socially just because it offers the same challenge to all, Yates (2009) suggests that an emphasis on 'the best that has been thought and said' (p. 22) fails to prepare students for a changing world and Zipin, Fataar, and Brennan (2015) argue that the rationale for disciplinary knowledge, by presenting the purpose of schooling to be cognition, thereby overlooks its ethical dimension.

Other'fixes' were introduced via the raising of grade boundaries, replacement of modular with end-of-course examinations, the abolition of in-course resit examinations and of continuous assessment (Winter, 2014). This 'fixed' curriculum model was experienced first-hand by teacher participants in the subsequent examination period in a variety of practical ways: an increase in the number of examination questions without a proportionate increase in time available; in mathematics GCSE, a student had to achieve 12 more marks than the previous year to gain a grade C; vocational examinations which previously counted for 3-4 GCSE qualifications were redesigned to count for only one (Jo). Stakeholder David challenged the definition or fixing by examination boards of the correct historical knowledge for schools:

In History we now have the chief examiner writing the textbook and all you need to know to pass the exam is in there. To me that runs absolutely counter to what History is about: discussion, disagreement, agreement, different sources and everything else. And so you might argue it's producing clarity but it's removing the professionalism of teachers. It's saying here are the answers, and there's no contesting these answers. In History the answers are never straightforward. And the chief examiner sets the paper, writes the book, does the CPD you know.

Reminiscent of Apple's idea of the teacher-proof 'curriculum on a cart', (Apple \& Jungck, 2014, p. 136) such a programmatic engagement with knowledge arises through the assumed existence of right answers and the denial of complexity, multiple perspectives and other knowledge, even the unknowable. None the less, fixing school knowledge through examination specifications renders it more amenable to codification and commodification in the context of the need for efficiency and economy in the light of the privatization of examination boards. 


\section{'Levels of progress'}

GCSE grades are of key significance in the English education system because they form the foundation for public performance tables. Students' target GCSE grades are calculated on the basis of 'levels of progress' (LPs) over the 5 years leading up to the GCSE examination. Primary school teachers assess their students in English, mathematics and science at age 11 , just prior to moving to secondary school. These KS2 results are expressed as National Curriculum Attainment Levels (1-8 plus sub-levels A-C). DfE and Ofsted policy compel schools to aim to increase pupils' attainment by 3-4 levels between secondary school entrance at 11 and 16 years (GCSE, KS4). But GCSE grades are currently presented in the form of letter grades, so teachers use official 'transition matrices' to translate end of KS2 'levels' to GCSE target 'grades' (Ofsted/DfE, n.d.).

Problems arise with this system when primary school teachers focus on test preparation to maximize pupil performance for the published KS2 performance tables (Collins, Reiss, Stobart, \& Collins, 2010). On entering secondary school, KS2 test scores form the basis for calculating target GCSE (KS4) grades, but as a result of teaching to the test, together with inadequacies in terms of validity of national testing (Stobart, 2008) in primary schools, pupils' target GCSE grades may be 'inflated' (Collins et al., 2010), and secondary school teachers face difficulties supporting pupils to meet target GCSE grades. This focus on levels of progress and GCSE grades illustrates a conundrum for teachers:

I think the dilemma is now we have to show four levels of progress for our students to be classed as a 'Good School'. At the same time you've got that argument 'But we need to get the kids at five $A^{*} s$ to $C$ '. So there are students who, on paper, will never get higher than an $E$ or a D. Yet at the same time, as a department, you also need to try and get those Cs up. So even at four levels of progress it puts them at a D but as a department you still need them to get the $A^{*} s$ to C. (Frances, teacher)

One initiative recently introduced by both Ofsted and DfE (DfE, 2014) to monitor teachers regarding 'Progress Over Time' is for inspectors to examine students' books for evidence of progress through marking. Some schools interpret this policy as teachers marking every piece of work and one teacher identified marking workload as an issue:

One of the things teachers are really struggling with at the moment is marking load. Because there is all this 'marking has to show impact'. So it's not that we've just marked your book, you have to see the impact for the kids. At the moment in a lot of schools everything has to be marked really in-depth. And you just can't do it. You just haven't got time. You can't spend five hours a night marking. (Claire, teacher)

Ball et al. (2011a, 2011b) acknowledge that teachers relate to and engage with policies in different ways in different contexts, yet, remarks above resonate with findings in their research schools, that teacher overload, time poverty and lack of autonomy are common occurrences.

\section{Data management}

The data management system in each school plays an important role in receiving, storing, analysing and delivering student data. At individual student level, in one participant's school, data are collected, stored, analysed and mined for reporting and intervention using the schools' management information system (SIMS). Data managers or teachers enter a host of data into the system, such as attendance, KS2 test levels, regular assessments, target GCSE grades, free school meals, behaviour, special educational needs, allergies, doctor's contact 
details and attitude to learning. In this school, data are then 'trawled', analysed and reported to parents three times per year for each year group except Yr 11 (the year in which students take their GCSE examination). Five 'trawls' take place for Yr 11 students. SIMS is not only used to predict and monitor academic progress, as a teacher participant explained:

And then with this data, someone filters out all the people who've got a code, like code $\mathrm{C}$ for confidence and then they set up a nurture group where all the under-confident people can have some work on being confident. And all the ones whose attendance is poor, the attendance guys get to work on them. So you know, it's quite good at targeting support. (Gordon)

Hence, transparency is assured because students are 'known' through their metrics. A technical evidence base is important in order to demonstrate 'what works' and how to best achieve value and equity in schooling. Several problems arise with the assumption of transparency, however. First, the technical procedures involved in the metrics do not reveal or question the 'values internal to the logic of the testing regime' (Sellar, 2013, p. 6), nor the provenance of those values. Second, an assumption exists that human subjects can be comprehensively 'known' and domesticated into particular predetermined moulds through calculative processes. Third, such technical procedures have profound 'perverse effects' of promoting 'game-play' on the part of policy-makers in this high-risk endeavour (Lingard \& Sellar, 2013) as well as misjudgement in assigning descriptors that form the basis of decision-making (Lingard et al., 2012).

At local and national levels, data comparison is a priority and schools in disadvantaged areas which recruit high levels of recently arrived migrant pupils seem to be 'punished' by the system relative to schools serving economically advantaged areas:

\begin{abstract}
Although it is rising, I think the current Year $11 \mathrm{~s}^{5}$, the average point score on entry [in this school-CW] is 24 point something and the average across the country is 27 point something. Those kids are likely to be less able to remember things. And yes, there are a lot of very intelligent students in this school, no doubt about it, some of the most able but there is a great proportion of lower ability and lower academically intelligent students that come in these doors. And what's my favourite figure this year? That Southview High had an intake in Year 7 of $89 \%$ Level 5 s, so higher attainers, and we had an intake of $18.7 \%$ Level 5 s. $10 \%$ of our whole school cohort are Roma and many of these arrived after the start of Year 9 straight from Slovakia and could not speak English and will not be able to attain perhaps even a $\mathrm{G}$ but will count towards the progress measures. So the school last summer achieved $54 \% A^{*}-C$, take $10 \%$ off that, $44 \%$ is what it would be if we were doing as well as we did last year. (Jo)
\end{abstract}

\title{
Teaching to the test
}

The curriculum, in the eyes of the participants, was not only narrowed by the importance conferred on literacy and numeracy, the E-Bac and core knowledge, but also as a result of the high-stakes testing regime driving students and teachers towards top GCSE grades. One teacher said: 'Because assessment drives the curriculum we're all teaching and people say 'don't teach towards the tests', but if you've got any sense you'll teach towards the tests because then your students will do better in the tests and they'll have better life chances. So it's the test that drives the curriculum' (Jo).

Research indicates a number of effects of high-stakes testing. For example, Polesel et al. (2014) cite: limitation on learning appropriate for the modern world (Au, 2008), promotion of shallow and superficial learning (Lobascher, 2011), 'cramming' for tests (Cunningham \& Sanzo, 2002), shift to competitive and individualistic approaches (Reay \& Wiliam, 1999), teachers operating as technicians (Hargreaves, 1994) and reduction in curriculum 
responsiveness to cultural difference (Klenowski, 2010, 2011). In the meeting, stakeholders focused on curbs to teacher creativity in content and pedagogy and student reactions. Frances remarked: 'the number of kids who say to me they really loved History at KS3, but 'if I'd have known it was going to be this at GCSE I wouldn't have done it'. Another teacher echoed this point with'I think partly ... lack of imagination ... the kids are like: 'Miss, this is so boring. Teachers regretted the decrease in their creativity, saying that lessons could be 'more organic and inquiry-based' and 'things that take that little bit more time perhaps are being done less and less' ... 'because you're aware that you're being judged on data. So I think the key point is maybe the enriching side of things has taken a hit' (Gordon).

Participants described how pressure to support students to perform at a high level in GCSE necessitated the deployment of certain 'fixed' practices. David, stakeholder said: ... the number of teachers I talk to who say the only way kids can do well at GCSE is to spend two or three years, every single lesson has to be one aspect of GCSE assessment. And it's death by exams. It's the tail wagging the dog' and a teacher spoke about stage-managed 'recipe-following' (Perryman, 2006, pp. 157, 158):

Everything is very exam-driven. I think a lot is also driven by the inspection regime. Because if you're teaching a GCSE class and you don't model a GCSE answer and you don't talk about the difference between a $C, a B$, an $A$ and an $A^{*}$ and you don't get them to do a self-assessment and peer assessment, you're given a poor lesson grade. (Claire)

The effect of the focus on examination targets and 'inspection-ready' lessons is to deflect teachers' attention and engagement from the wider goals and processes of education, as this teacher explains:

But I think with the way you have to do things, you just don't think about the bigger picture do you? You can't think about what you've actually got because you've just got this end point that you're just drilling down to this end point of As to Cs, four LPs, you don't get time to have a look around and see what else you could do to get there. (Gordon)

\section{'Fixing' teachers}

One teacher responded to the question 'Is this data a good thing or ... does it have a downside to it?' with the following:

Well, as a subject leader it's a good thing. And I think as a classroom teacher it's a good thing. And as a parent it's a good thing. It's important to be able to measure progress that I want to know when I visit someone's class or someone visits my class: we want to know that there's an impact. It does have that perhaps unintended consequence of perhaps making the curriculum a little less creative and organic ... because our eye is on the progress levels ... because that's how teachers are being judged. (Gordon)

At the same time, he agreed with others in the group that teachers are in the firing line for blame if students' results do not meet predicted targets. Echoing Thompson and Cook (2014), participant teachers agreed that '... if your results are bad, you're made to feel like you're a bad person, never mind a bad teacher' (Claire). Such feelings arose amongst teachers in spite of recognition by senior staff of issues surrounding inappropriate designation of student targets, as discussed earlier:

When you raise concerns about patterns raised in the data, off the record your line manager will often agree with you but when push comes to shove it's the way it is. You're made to feel that if you're disagreeing with the data it's because you've done something wrong, you've failed in 
some way ... rather than listening to your professional judgment of 'Well actually I don't know where that number's come from but that kid can't do it' and I think that's a real shame. (Claire) She continued, remarking on the feelings of de-professionalization experienced under the recent policy reforms:

I do think that we're often not treated as professionals. A good example links back into the target-driven culture; there are kids whose targets are far too high ... and even if that kid is trying, they're always highlighted red in our school. And every data collection that goes home, they're red, no matter what they do, they just can't reach that level.

Drawing attention to the ethical and political relations arising when parents receive regular reports from school of the failure of their child to 'make the grade', Claire describes her emotional responses to the persistent labelling of students in relation to a target:

I think that as a teacher, as a professional, the person who inputs that data should listen to me saying 'Look, that kid is not going to get that target; can you just bring it down? They are trying but just so that every single data collection that goes home, they're not coloured in red. It would just be a confidence boost for that child'. But they won't do it. And that upsets me because I'm not trying to do it to cop out, I'm not trying to do it so I don't have to work. But as a professional for me to be worried about that child, I think you should reduce their target, and it won't be done. And that I find insulting.

Claire was compelled to comply with policy against her professional and personal beliefs because these struck against what was perceived and prized as the needs of the learner and of the school. But since the official interpretation of learners' needs is caught up in the culture of technical accountability, teachers are complicit as government surveillance agents, 'deliverers' and reporters of curriculum policy, a role in which not only are their voices not heard, but their consciousness and consciences co-opted into a new agenda (Ball, 2003, p. 218).

\section{'Fixing' students}

Within the context of raising standards in disadvantaged schools, three issues relating to 'fixing' students arose. The first concerns how ways of thinking about students under a highstakes assessment system adapt to fit the required discourse and output. A teacher remarked: '... I don't think you talk about students as students anymore, you talk about students as data'. Second, an 'economy of visibility' regarding student data profiles (Ball et al., 2012, p. 530 ) is evident in school policy, whatever emotional sensitivities it may confer:

For the kids with very high targets, there is a pressure to be continually achieving them and for the kids with very low targets, just how awful. Every GCSE class you walk into, you've got a sticker on the front of your book saying your target grade is $\mathrm{G}$; what does that do for your self-confidence? (Claire)

The ethical implications of public humiliation through objectification, differentiation and labelling are overlooked in the drive to raise standards. Third, when asked whether he thought that students felt the pressure of targets and if so, what the effects might be, a teacher replied:

Sometimes you have to negotiate and you do get that look of resignation of children when you're just trying to squeeze that little bit more out of them, whether it's time or paragraphs. They've done a nice piece of work and you just say 'Do you know what your target is? It's a B; your four LPs is a B'. And they know what that means, so they know that we're under pressure to get that out of them. And yeah, it does maybe put a strain on the relationship every now and again. (Gordon) 
Another form of 'fixing' students is evident in the ways the high-stakes system influences student access to specific subject choices (Hobbs, 2016). Given the pressure for schools to maximize their percentage of 5 or more $A^{*}-C$ grades, together with the introduction of a more intellectually challenging curriculum content and structure, a dilemma arises for teachers about which students they allow to study their subject at GCSE level. Teacher participants agreed that geography and history GCSE have come under tighter control as'more academically-minded subjects', with 'large blocks of writing' that involve more'independent thinking' than other subjects. As a result, they claimed that students with English as an additional language and the so-called 'lower ability' students were not keen or equipped to tackle the 'constant writing and research and being independent and asking the right questions and the higher order thinking that goes with it'. An important first issue arises that if levels of literacy and independent and academic thinking are considered to be student problems, then what responsibility rests with curriculum makers to construct, and with teachers to teach, a curriculum which is appropriate for students across a range of different characteristics. One stakeholder aptly remarked: 'If you've got nothing you want to read, why would you want to read? For a lot of children, you want something that they're interested in to read and write about' (David).

A second issue raised in the meeting limiting access to high-quality teaching in geography and history is how schools draw on non-specialist teachers at KS3 because the subject-qualified teachers are 'creamed off' to teach the high-stakes GCSE classes. Third, teachers recognized the dilemma presented in giving all students access to their subject:

We had to look at the data of some of our students, so for example the ones that had taken History GCSE ... and there is a sheer panic in our History teacher's voice that she will not be able to get them the results that the school needs by the end of the two years. Should it stop a child doing it? Absolutely not. (Frances)

Under the performativity regime, however, the counter-argument from the schools' perspective was posed by a stakeholder:

If you take the approach where everyone can have a go and it doesn't matter if you don't get a C, there are trade-offs in terms of, well, they could actually be doing another subject, where they could get a higher grade. (Jane)

The datafication of student identities makes students visible to others such that each is considered to be comprehensively known (albeit according to the predefined requirement of the system). Knowledge of students allows for their fine-grained differentiation, labelling and ranking around predetermined norms which are then used as a basis for distributing 'opportunity, dignity and esteem, both by attention to and neglect of the individual within systems of comparison, evaluation and documentation' (Ball et al., 2012, p. 530).

\section{Conclusion}

This paper investigates educators' experiences of curriculum policy reform in terms of its ethical relations under conditions of technical accountability. Participants draw attention to their everyday lived experiences whilst working under totalizing regimes that regulate their professional lives in ways that counteract their professional and ethical judgements, including practices involving the humiliation and coercion of students, teachers and parents. Levinas works beyond the constraints of the metaphysics of humanism, is concerned with the instability of language, totalizing discourses and ethical responsibility in relations of 
difference and thereby allows us to think outside a prescribed programme of technical accountability to see what or who is denied ethical relations when such a programme dominates the education system.

Some argue that education policies like the ones reported here are constructed by technocrats remote from the experiences of classrooms in disadvantaged schools (Coffield, 2012, p. 140) and unaware of the profound and reductive effects of analysing condensed student data to assess a limited range of skills across a student's school career (Polesel et al., 2014, p. 653). Nevertheless, policies heralding curriculum standardization, high-stakes testing and datafication conveniently deflect attention about and responsibility for educational accountability from government to teachers and thereby operate as what Lipman describes as'coercive government' $(2013$, p. 558) at a time when disparagement of public services globally neatly propels the shift towards privatization. Lipman states:'systems of accountability make education legible for the market and private appropriation, mark schools and school districts and pathological and in need of authoritarian governance, and justify minimalist schools in areas of urban disposability' (p. 558).

Complying with policy requirements also deflects attention from broader philosophical and ethical questions. The regulatory curriculum system locks students and teachers into a totalizing technical-rational framework in such an all-embracing way that spaces for considering, deliberating about and acting on ethical responsibilities for and to others are elided, screened away, hidden, denied. Conceptualizing education through pre-defined way of being, and understanding student and teacher subjectivities as available for moulding into prescribed forms seem not only illustrative of extreme hubris, but to confer violence on those compelled to engage as well as to close down a wide array of alternative ways of being. Although current dominant pre-defined curriculum standards and high-stakes assessment appear to offer rigorous educational accountability, a closer look finds practice lacking with regard to ethical responsibility. In other words, what the philosophical perspective and data in this paper illuminate is how the technical-rational discourse fails to address through its quest for pre-ordained order, the ethical importance of the singularity and uniqueness of the subject and of human relationality in education.

Education systems increasingly controlled and subject to surveillance through curriculum policy influence who teachers and students are and who they will become, in other words, their sense of self, their subjectivity. The dominant technical-rational curriculum system claims to be a comprehensive, high trust system for educational improvement. A closer look through the lens of a philosophical 'fix' reveals a deficit in ethical responsibility, brought about by the system's reliance on standardization, datafication and conformity around predetermined and externally imposed norms and neglecting alternative possibilities of being.

\section{Notes}

1. Also: below average \% of pupils at the end of KS4 making expected progress in English (national median for $2010=72 \%$ ); and below average $\%$ of pupils at the end of KS4 making expected progress in maths (national median for $2010=65 \%$ ) (DfE, 2010b).

2. 'Inter-professional focussed conversations' form a development of Clough and Nutbrown's (2002, p. 84) 'focussed conversations' as the former were conducted in the study reported here with education stakeholders from different professional fields with interests in school geography and history curricula and assessment. 
3. (1) Is there a problem? (2) what are the problem/s? (3) what are the needs of students? (4) what are the needs of teachers? (5) what questions do we need to ask and answer?

4. The English Baccalaurate (E-Bac) is a performance indicator, i.e. a means of ranking schools in the GCSE examination league table.

5. Students aged $15-16$ years.

\section{Disclosure statement}

No potential conflict of interest was reported by the author.

\section{Notes on contributor}

Christine Winter is Senior Lecturer in Educational Studies and Education Pathway Lead for the White Rose Doctoral Training Centre, a postgraduate training consortium of the Universities of Sheffield Leeds and York. Her research focuses on secondary school curriculum with specific interests in curriculum knowledge, politics, policy and practice, globalization and global citizenship education.

\section{References}

Apple, M. J., \& Jungck, S. (2014). Official knowledge: Democratic education in a conservative age (3rd ed.). London: Routledge.

Abrams, L. M. (2004). Teachers'views on high-stakes testing: Implications for the classroom. Tempe, Arizona: Education Policy Research Unit College of Education Arizona State University EPSL-0401-104-EPRU.

$\mathrm{Au}, \mathrm{W}$. (2007). High-stakes testing and curricular control: A qualitative metasynthesis. Educational Researcher, 36, 258-267.

$\mathrm{Au}, \mathrm{W}$. (2008). Devising inequality: A Bernsteinian analysis of high-stakes testing and social reproduction in education. British Journal of Sociology of Education, 29, 639-651.

$\mathrm{Au}, \mathrm{W}$. (2011). Teaching under the new Taylorism: High-stakes testing and the standardization of the 21 st century curriculum. Journal of Curriculum Studies, 43, 25-45.

Baker, E. L., Barton, P. E., Darling-Hammond, L., Haertel, E., Ladd, H. F., Linn, R. L., ... Shepard, L. A. (2010). Problems with the use of student test scores to evaluate teachers. Unit Briefing Paper 278. Washington, DC: Policy Institute.

Ball, S. J. (2003). The teacher's soul and the terrors of performativity. Journal of Education Policy, 18, 215-228.

Ball, S. J., Maguire, M., Braun, A., \& Hoskins, K. (2011a). Policy subjects and policy actors in schools: some necessary but insufficient analyses. Discourse: Studies in the Cultural Politics of Education, 32, 611-624.

Ball, S. J., Maguire, M., Braun, A., \& Hoskins, K. (2011b). Policy actors: Doing policy work in schools. Discourse: Studies in the Cultural Politics of Education, 32, 625-639.

Ball, S. J., Maguire, M., Braun, A., Perryman, J., \& Hoskins, K. (2012). Assessment technologies in schools: 'deliverology' and 'the play of dominations'. Research Papers in Education, 27, 513-533.

Barber, M. (2007). Instruction to deliver: Tony Blair, the public services and the challenge of delivery. London: Methuen.

Barrett, B. D. (2009). NCLB and the assault on teachers' professional practices and identities. Teaching and Teacher Education, 25, 1018-1025.

Biesta, G. J. J. (2010). Good education in an age of measurement: Ethics, politics democracy. London: Paradigm.

Braun, A., Ball, S. J., Maguire, M., \& Hoskins, K. (2011). Taking context seriously: Towards explaining policy enactments in the secondary school. Discourse: Studies in the Cultural Politics of Education, 32, 585-596.

Braun, V., \& Clarke, V. (2006). Using thematic analysis in psychology. Qualitative Research in Psychology, $3,77-101$. 
Cherryholmes, C. H. (2002). Curriculum ghosts and visions: and what to do? In W. E. Doll \& N. Gough (Eds.), Curriculum visions (pp. 116-129). Oxford: Peter Lang.

Clough, P., \& Nutbrown, C. (2002). A student's guide to methodology. London: Sage.

Coffield, F. (2012). Why the Mc Kinsey reports will not improve school systems. Educational Researcher, $36,258-267$.

Collins, S., Reiss, M., \& Stobart, G. (2010). What happens when high-stakes testing stops? Teachers' perceptions of the impact of compulsory national testing in science of 11-year-olds in England and its abolition in Wales. Assessment in Education: Principles, Policy and Practice, 17, 273-286. 10.1080/0969594X.2010.496205

Comber, B. (2012). Mandated literacy assessment and the reorganisation of teachers' work: Federal policy, local effects. Critical Studies in Education, 53, 119-136.

Comber, B., \& Nixon, H. (2009). Teachers' work and pedagogy in an era of accountability. Discourse: Studies in the Cultural Politics of Education, 30, 333-345.

Cunningham, W., \& Sanzo, T. (2002). Is high-stakes testing harming lower socio-economic schools? National Association of Secondary School Principals (NASSP) Bulletin, 86, 62-75.

Darling-Hammond, L. (2010). The flat world and education: How America's commitment to equity will determine our future. New York, NY: Columbia University: Teachers' College Press.

DfE. (2010a). The importance of teaching: The schools white paper. Cm 7980. London: Her Majesty's Stationery Office.

DfE. (2010b). School performance tables 2010 Expected levels of secondary school performance. Retrieved May 8, 2016, from http://www.education.gov.uk/schools/performance/archive/ schools_10/s2.shtml\#expectedlevels

DfE. (2014). Key stage 2 - Key stage 4 progress measures. file:///C:/Users/Chris/Downloads/Guide_to_KS2KS4_progress_measures_2014[1]\%20(1).pdf.Retrieved January14, 2016, from http://www.education. gov.uk/schools/performance/archive/schools_10/s11.shtml

Dulfer, N., Polesel, J., \& Rice, S. (2012). The experience of education: The impacts of high-stakes testing on school students and their families: An educator's perspective. Sydney: Whitlam Institute University of Western Sydney.

Eppert, C. (2008). Emmanuel Levinas, literary engagement and literature education. In D. Egea-Khuehne (Ed.), Levinas and education (pp. 67-84). London: Routledge.

Gerrard, J., \& Farrell, L. (2013). 'Peopling' curriculum policy production: researching educational governance through institutional ethnography and Bourdieuian field analysis. Journal of Education Policy, 28(1), 1-20.

Hargreaves, A. (1994). Changing teachers changing times: Teachers' work and culture in the post-modern age. London: Cassell.

Henig, J. R. (2013). Foreword. In D. Anagnostopoulos, S. A. Rutledge, \& R. Jacobsen (Eds.), The Infrastructure of accountability: Data use and the transformation of American Education. Cambridge, MA: Harvard Education Press. vii-xiii.

Hobbs, K. (2016). The constitution and implementation of the English Baccalaureate: Implications for educational equality (Unpublished EdD thesis). Sheffield: University of Sheffield School of Education.

Hursh, D. (2013). Raising the stakes: High-stakes testing and the attack on public education in New York. Journal of Education Policy, 28, 574-588.

Keddie, A. (2013). Thriving amid the performative demands of the contemporary audit culture: A matter of school context. Journal of Education Policy, 28, 750-766.

Kierkegaarde, S. (1850). Letter. 263. p. 357f. April, 1850 to Emile Boesen. Retrieved from http:// sorenkierkegaard.org/kierkegaard-letters-documents.html

Klenowski, V. (2010, November 10-15). Are Australian assessment reforms fit for the purpose? Lessons from home and abroad. Queensland Union of Teachers Professional Magazine, 10-15.

Klenowski, V. (2011). Assessment for Learning in the accountability era: Queensland Australia. Studies in Educational Evaluation, 37, 78-83.

Leat, D., Livingston, K., \& Priestley, M. (2014, October). Curriculum deregulation in England and Scotland: Different directions of travel? Conference presentation 'Do Teachers Matter; but how?' Linnaeus University, Vaxjo, Sweden.

Levinas, E. (1969). Totality and infinity: An essay on exteriority. (A. Lingis, Trans.). Pittsburgh, PA: Duquesne. 
Lingard, B. (2011). Policy as numbers: Ac/counting for educational research. The Australian Educational Researcher, 38, 355-382.

Lingard, B., Creagh, S., \&Vass, G. (2012). Education policy as numbers: Data categories and two Australian cases of misrecognition. Journal of Education Policy, 27, 315-333.

Lingard, B., Martino, W., \& Rezai-Rashti, G. (2013). Testing regimes, accountabilities and education policy: Commensurate global and national developments. Journal of Education Policy, 28, 539-556.

Lingard, B., \& Sellar, S. (2013). 'Catalyst data': Perverse systemic effects of audit and accountability in Australian schooling. Journal of Education Policy, 28, 634-656.

Lingard, B., Sellar, S., \& Savage, G. C. (2014). Re-articulating social justice as equity in schooling policy: The effects of testing and data infrastructures. British Journal of Sociology of Education, 35, 710-730.

Lipman, P. (2013). Economic crisis, accountability, and the state's coercive assault on public education in the USA. Journal of Education Policy, 28, 557-573.

Lobascher, S. (2011). What are the potential impacts of high-stakes testing on literacy education in Australia? Australian Journal of Language and Literacy, 34, 9-19.

Lyotard, J.-L. (1984). The postmodern condition: A report on knowledge. (G. Bennington and B. Massumi, Trans.). Manchester, NH: Manchester University Press.

Macedo, E. (2013). Equity and difference in centralized policy. Journal of Curriculum Studies, 45, 28-38. Maguire, M., Hoskins, K., Ball, S. J., \& Braun, A. (2011). Policy discourses in school texts. Discourse: Studies in the Cultural Politics of Education, 32, 597-609.

Ofsted/DfE. (n.d.). Transition matrices (RAISEonline). Retrieved January 14, 2016, from https://www. raiseonline.org/documentlibrary/ViewDocumentLibrary.aspx

Pedulla, J. L., Abrams, L. M., Madaus, G. F., Russell, M. K., Ramos, M. A., \& Miao, J. (2003). Perceived effects of state-mandated testing programs on teaching and learning: Findings from a national survey of teachers. National Board on Educational Testing and Public Policy. Boston, MA: Lynch School of Education, Boston College.

Perreault, G. (2000). The classroom impact of high-stress testing. Education, 120, 705-710.

Perryman, J. (2006). Panoptic performativity and school inspection regimes: Disciplinary mechanisms and life under special measures. Journal of Education Policy, 21, 147-161.

Polesel, J., Rice, S., \& Dulfer, N. (2014). The impact of high-stakes testing on curriculum and pedagogy: A teacher perspective from Australia. Journal of Education Policy, 29, 640-657.

Ranson, S. (2003). Public accountability in the age of neo-liberal governance. Journal of Education Policy, 18, 459-480.

Reay, D., \& Wiliam, D. (1999). 'I'll be a nothing': Structure, agency and the construction of identity through assessment. British Educational Research Journal, 25, 343-354.

Rizvi, F. \& Lingard, B. (2010). Globalizing education policy. London: Routledge.

Rose, N. (1999). Powers of freedom. Cambridge: Cambridge University Press.

Sahlberg, P. (2011). Finnish lessons: What can the world learn from educational change in Finland?. New York, NY: Teachers' College Press.

Sellar, S. (2009). The responsible uncertainty of pedagogy. Discourse: Studies in the Cultural Politics of Education, 30, 347-360.

Sellar, S. (2013). Transparency and opacity: Levinasian reflections on accountability in Australian schooling. Educational Philosophy and Theory, 47, 118-132.

Sellar, S., \& Lingard, B. (2013). The OECD and global governance in education. Journal of Education Policy, 28, 710-725.

Singh, P., Thomas, S., \& Harris, J. (2013). Recontextualising policy discourses: A Bernsteinian perspective on policy interpretation, translation, enactment. Journal of Education Policy, 28, 465-480.

Stobart, G. (2008). Testing times: The uses and abuses of assessment. London: Routledge.

Strhan, A. (2012). Levinas, subjectivity, education: Towards an ethics of radical responsibility. Oxford: WileyBlackwell.

Thompson, G. (2012). Effects of NAPLAN. Executive summary. Murdoch, Perth: Murdoch University.

Thompson, G., \& Cook, I. (2014). Education policy-making and time. Journal of Education Policy, 29, 700-715.

Todd, S. (2001). Bringing more than I contain': Ethics, curriculum and the pedagogical demand for altered egos. Journal of Curriculum Studies, 33, 431-450. 
Todd, S. (2003a). Learning from the other: Levinas, psychoanalysis and ethical possibilities in education. New York: University of New York Press.

Todd, S. (2003b). Introduction: Levinas and education: The question of implication. Studies in Philosophy and Education, 22, 1-4.

Winter, C. (2009). Places, spaces, holes for knowing and writing the earth: The Geography curriculum and Derrida's Khora. Ethics and Education, 4, 337-354.

Winter, C. (2011). Curriculum knowledge and justice: Content, competency and concept. Curriculum Journal, 22, 337-364.

Winter, C. (2014). Curriculum knowledge, justice, relations: The Schools'White Paper (2010) in England. Journal of Philosophy of Education, 48, 276-292.

Yates, L. (2009). From curriculum to pedagogy and back again: Knowledge, the person and the changing world. Pedagogy, Culture and Society, 17, 17-28.

Zipin, L., Fataar, A., \& Brennan, M. (2015). Can social realism do social justice? Debating the warrants for curriculum knowledge Selection. Education as Change, 19, 9-36. 